Review

\title{
Endoscopic Skull Base Surgery
}

\author{
Steve C Lee, MD, PhD · Brent A Senior, MD \\ Department of Otolaryngology-Head and Neck Surgery, University of North Carolina at Chapel Hill, NC, USA
}

Endoscopic skull base surgery has undergone rapid advancement in the past decade moving from pituitary surgery to suprasellar lesions and now to a myriad of lesions extending from the cribriform plate to $\mathrm{C} 2$ and laterally out to the infratemporal fossa and petrous apex. Evolution of several technological advances as well as advances in understanding of endoscopic anatomy and the development of surgical techniques both in resection and reconstruction have fostered this capability. Management of benign disease via endoscopic methods is largely accepted now but more data is needed before the controversy on the role of endoscopic management of malignant disease is decided. Continued advances in surgical technique, navigation systems, endoscopic imaging technology, and robotics assure continued brisk evolution in this expanding field.

Key Words. Endoscopic, Skull base, Paranasal sinuses, Parasellar, Endonasal

\section{HISTORICAL PERSPECTIVE}

The history of endoscopic skull base surgery is de facto the history of pituitary surgery. The first pituitary operation was likely performed by Sir Victor Horsley in 1889 via a transfrontal approach though he did not publish his results (1). His compatriots, Caton and Paul, were the first to publish the results of this operation in 1893 (2) in which they reported that their patient was cured of his headaches for the three months he survived post operatively. But, it is Schloffer who is widely regarded as the father of modern pituitary surgery. In 1906 he published a seminal paper discussing the possibility of pituitary surgery via a transsphenoidal approach (3) and performed this operation on March 16, 1907. The operation was performed via nasal translocation and lasted about $75 \mathrm{~min}$. Though there were no intraoperative complications, the patient died two months later and on autopsy was found to have hydrocephalus as a result of residual tumor blocking the foramen of Monro (4). Then in 1910, Oskar Hirsh, an otolaryngologist, introduced a transseptal, transsphenoidal approach to the pituitary gland (5), an operation which is still in use today. Cushing performed his first pituitary operation in 1909 (6) using Schloffer's method but then rapidly adopted Hirsh's approach adding a sublabial incision and a headlamp to improve visualization of the sella. Using this approach he performed 231 oper-

\footnotetext{
- Received June 12, 2008

Accepted after revision June 16, 2008

- Corresponding author : Steve C Lee, MD, PhD

Department of Otolaryngology-Head and Neck Surgery, University of

North Carolina at Chapel Hill, Campus Box \#7070, 101 Manning Drive Chapel Hill, NC 27599, USA

Tel : +1-919-966-4131, Fax : +1-919-966-7941

E-mail : neoender@gmail.com
}

ations with a $5.6 \%$ mortality rate $(7,8)$. However, because of difficulties with cerebrospinal fluid (CSF) leak, hemorrhage control, post operative cerebral edema, and concerns regarding vision outcomes and recurrence he eventually abandoned the transsphenoidal approach and went to a transcranial approach. This was a large setback for the transsphenoidal approach as it led to the vast majority of pituitary operations being performed transcranially for the next $35 \mathrm{yr}$.

During this period, the transsphenoidal approach was championed by two surgeons. Hirsch continued to perform transphenoidal hypophysectomy and by 1937 had performed the operation on 277 patients with a mortality rate of $5.4 \%$ (9). After being displaced from Austria by the Nazis shortly thereafter, he emigrated to the US and continued to operate at Massachusetts General Hospital in collaboration with a neurosurgeon, Hannibal Hamlin. The other surgeon who kept the technique alive was Norman Dott, a British neurosurgeon who learned the approach in 1923 from Cushing and by 1956 had performed 80 procedures with no deaths (8).

The modern advent of the transsphenoidal approach as the preferred approach to the pituitary began in 1956 when a French neurosurgeon, Gerard Guiot, learned the technique from Dott and brought it back to Paris and reintroduced it to skeptical colleagues. He ultimately performed over 1,000 transsphenoidal hypophysectomies and also introduced the use of intraoperative fluoroscopy $(8,10,11)$. A student of Giuot, Jules Hardy revolutionized the transsphenoidal pituitary approach when he introduced the use of the operating microscope and microsurgical instrumentation in 1967. The microscope with increased illumination and magnification permitted a more thorough and safer resection without deaths or major morbidities $(10,11)$. Indeed, Hardy's 
contributions led to a paradigm shift in pituitary tumor surgery. Previously, the operation was performed to debulk large tumors off the optic apparatus, but now microsurgical techniques were introduced allowing for surgical cure of hormonal disease in microadenomas.

Although the procedure described by Hardy underwent numerous modifications (including extended approaches to other skull base sites: clival and suprasellar tumors as well as cavernous sinus lesions), it was the main procedure performed by neurosurgeons for removal of pituitary tumors from the 1960's through the early 1990's.

The dawn of endoscopic pituitary and skull base surgery was dependent on several technological advances, the most obvious of which is the endoscope. The first endoscope is credited to Philipp Bozzini, a German physician, who demonstrated the "Lichtleiter", a candlelit tube, in 1806 to the Academy of Medicine in Vienna (12). This was vastly improved in 1877 by Max Nitze, a German urologist, with the addition of lenses for magnification and an internal light source noting "to light up a room one must carry the lamp inside (13)." His first endoscope used a water-cooled platinum wire for illumination but Edison's invention of the incandescent bulb in 1879 allowed the development of a cystoscope

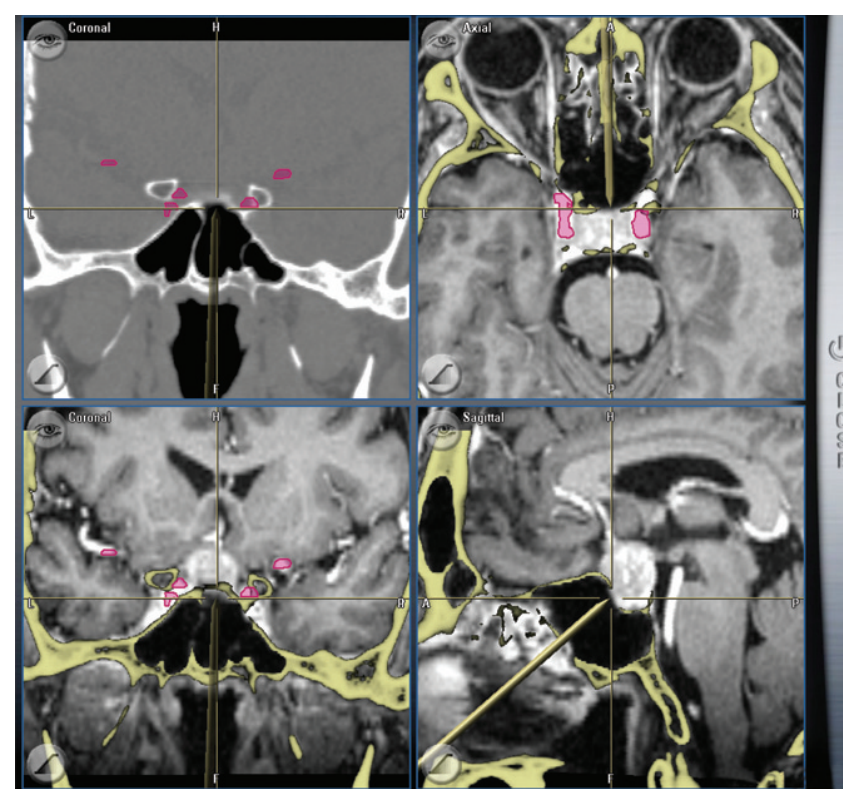

Fig. 1. Image guidance navigation system showing fusion of MRI and CT. The fusion of CT and MRI data allows the surgeon to have information on bony anatomy, tumor position and size, as well as location of critical structures such as the carotid artery and optic nerve.
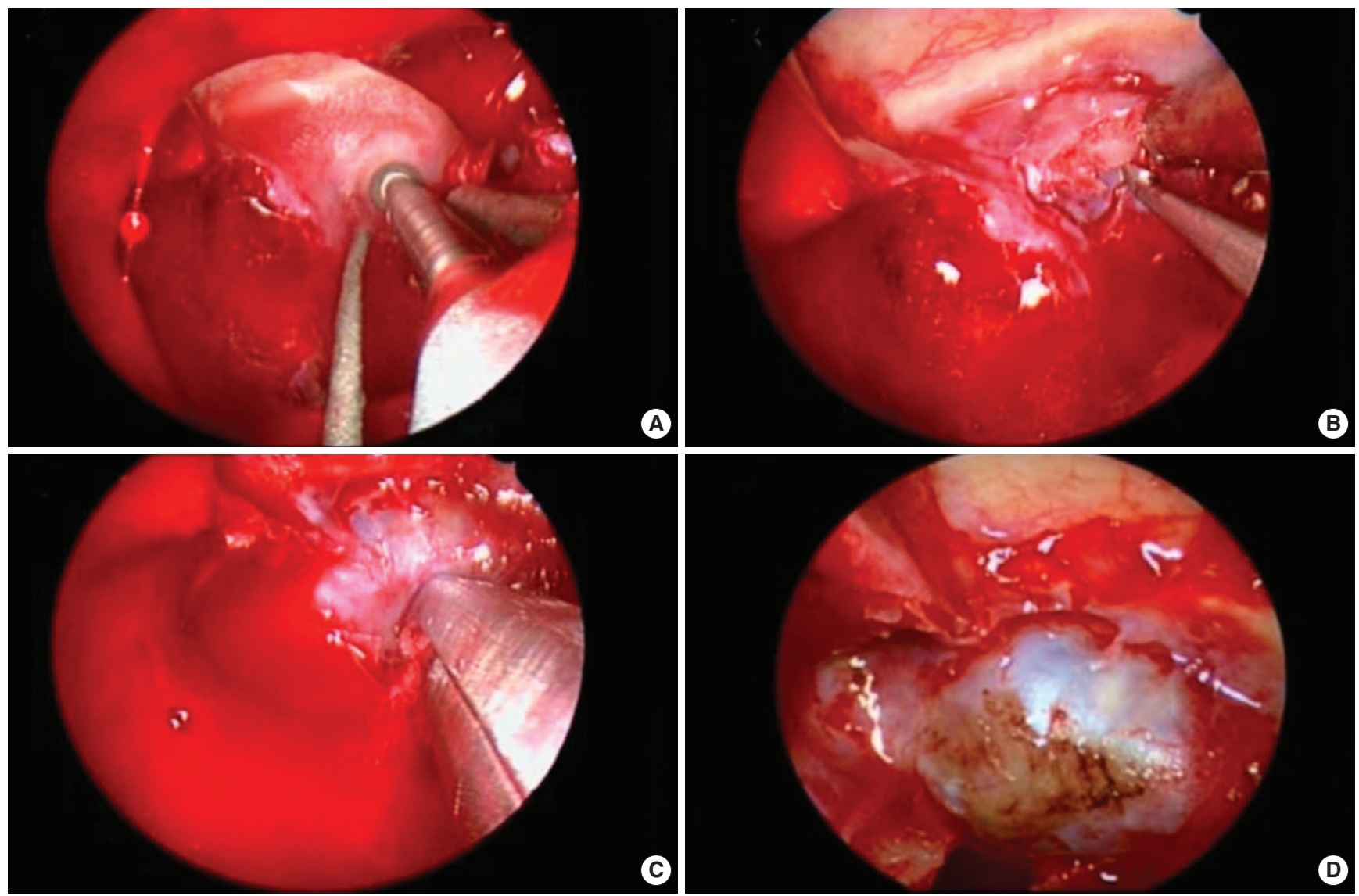

Fig. 2. Sellar opening. (A) After the sphenoid sinus is wide opened, the sella is drilled with an irrigating drill with a diamond burr until the bone is eggshell thin. (B) Thin bone is then fractured and removed with curettes. (C) Bony opening is then enlarged with kerrison rongeurs. (D) After the dura is exposed, bipolar coagulation is performed before opening of the dura. 
that no longer required water cooling. Using his invention, Nitze was the first person to perform endoscopic surgery with wire loops and to take endoscopic pictures. The next technological breakthrough occurred almost a century later when Harold Hopkins in 1960 vastly improved optical efficiency by inserting glass rods and neutral gas between the lenses. Around the same time, Basil Hirschowitz, an American gastroenterologist, developed a flexible endoscope using fiberoptics. The modern rigid endoscope was invented by Karl Storz in 1965 when he combined the optical rod system of Hopkins and used fiberoptics to carry illumination down to the tip of the endoscope (14). This endoscope allowed radically improved visualization offering magnified panoramic views from the tip of a narrow caliber instrument. Other important developments included the invention of computed tomography, image guidance systems (Fig. 1), powered instrumentation (Fig. 2) and the charged coupled device camera.

In 1901, Hirschman used a modified cystoscope to inspect the maxillary sinus but it was not until the modern endoscope was invented that endoscopic surgery of the paranasal sinuses became practical. This started with Messerklinger who in the 1970s published seminal work on endoscopic diagnosis and management of inflammatory disease of the sinuses (15). Endoscopic surgery of the paranasal sinuses rapidly advanced and was popularized by the work of Kennedy, Stammberger and others starting in the 1980s. Its use in pituitary surgery was actually first mentioned as a complementary procedure by Guiot, however, widespread use of the endoscope in pituitary surgery did not follow (10). Endoscopic surgery of the pituitary was revisited by Jankowski in 1992 (16) but it was the landmark paper by Jho and Carrau in 1997 that marked the beginning of modern endoscopic pituitary surgery. In their series of 50 patients, they reported the results of 48 operations which were purely endonasal, endoscopic, transsphenoidal approaches to the pituitary and noted the safety, efficacy and decreased morbidity of this technique (17). This was

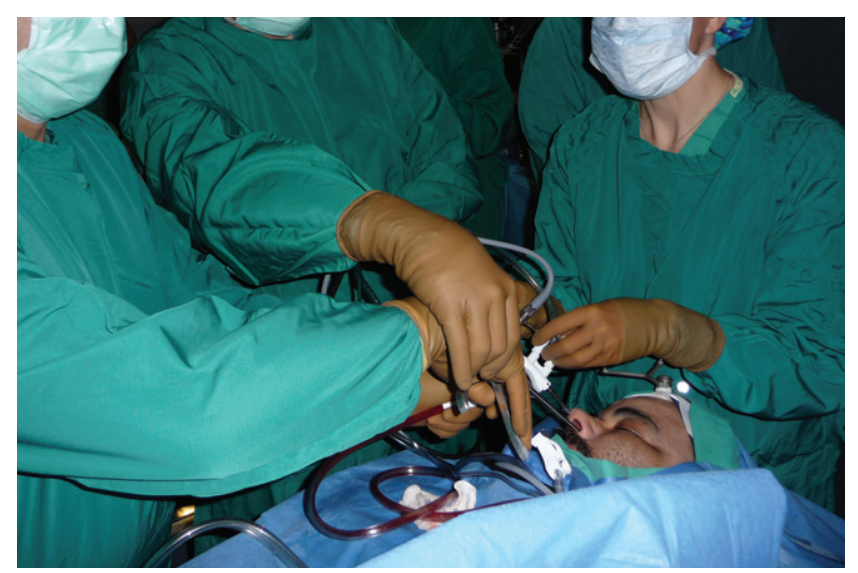

Fig. 3. Four hand technique. One surgeon generally holds the endoscope and a suction while the other surgeon dissects with two hands. In this picture, the teaching surgeon is reaching in with forceps to remove specimen for frozen section. quickly followed by a report by Cappabianca et al. who developed dedicated endoscopic equipment and suggested technical improvements (18). It is now clear that compared to transsphenoidal surgery using an operative microscope, endoscopic surgery offers shorter operative times, less intraoperative blood loss, superior differentiation between normal glandular tissue and tumor, better images of intrasellar and parasellar structures, reduced hospital stay, improved patient satisfaction, and decreased need for nasal packing (9).

It was not long afterward that endoscopic approaches beyond the sella were described. Access to the suprasellar lesions by taking down the planum sphenoidale using a microscope was decribed by Laws et al. in 1980 (19) and this same approach was adapted for endoscopy. Descriptions of endoscopic access to the cavernous sinus, clivus, odontoid process, pterygopalatine fossa, petrous apex, and midline anterior cranial fossa have now all be published (2041). These more advanced skull base operations require the use of two surgeons operating with four hands (Fig. 3).

There are several distinct anatomic regions of the skull base that are accessible via a transnasal endoscopic approach: cribriform, parasellar, clivus, spinomedullary junction, petrous apex, pterygopalatine and infratemporal fossa. It is useful to consider each region separately as each has its own set of anatomic constraints and indeed, a modular system of approaches based on these anatomic subunits have been proposed by Kassam et al. (29-31). In addition, there are specific histopathologies that are more commonly encountered in each region.

\section{CRIBRIFORM LESIONS}

Lesions that involve the cribriform plate include olfactory groove meningioma, esthesioneuroblastoma, adenocarcinoma, squamous cell carcinoma, sinonasal undifferentiated carcinoma, mucosal melanoma and many others. Of these rare lesions, the most published data on endoscopic resection is on esthesioneuroblastomas. There are several cases series on endoscopic resection of esthesioneuroblastomas but each report only represents a handful of patients. Unger et al. first published a series of six patients treated endoscopically and with a followup of 57 months, they achieved $100 \%$ disease specific survival (36). Surgical margins were not obtained in that study but no obvious disease was left behind. Poetker et al. reported on 5 cases with 2 recurrences, both in Kadish $\mathrm{C}$ disease (42). Their report on 40 patients included 24 with benign pathology, mostly inverting papilloma, and 16 with malignant pathology, mostly esthesioneuroblastoma. The recurrence rate was $4 \%$ for benign disease and $31 \%$ for malignant disease with a mean followup of 22 and 51 months respectively. Lund et al. found overall survival of $89 \%$ and disease free survival of $56 \%$ in a cohort of 11 patients treated endoscopically (43). This series was limited to patients with Kadish A and B disease with the author's current preference for open craniofacial resection for 
Kadish C diease. Another report on 18 patients treated over a $25 \mathrm{yr}$ period had 3 patients treated with endoscopic resection, of which one patient had two recurrences and ultimately underwent open craniofacial resection (44). Castelnuovo et al. have also described their experience in ten patients who underwent endoscopic resection, all with negative margins and no local recurrences with median follow up of 37 months (45). They were able to save olfactory function in all their patients by performing a unilateral cribform excision and sparing the contralateral cribriform plate, an idea that has been advocated by other authors (46). Similarly, another Italian group treated nine patients with no evidence of disease with a mean followup of 42 months (47). That study only included Kadish A and B disease as the authors felt as Lund et al. that Kadish $\mathrm{C}$ disease was best treated by traditional craniofacial resection. Dave et al. treated nine patients with one recurrence (46). The lack of en bloc resection has often been a criticism of endoscopic surgery when managing malignant disease (48) however, in this study, the authors were able to achieve what they considered to be en bloc resection in about half of their patients and negative margins in all patients. Also, many authors have suggested that piecemeal resection does not appear to affect patient outcomes provided that negative margins are ultimately achieved $(46,49-51)$. Others have suggested that though en bloc tumor removal is not important, en bloc removal of the area of invasion or tumor origin is crucial (52). The most recently published data on 23 patients of all Kadish stages treated at University of Miami and University of Pittsburgh demonstrated no evidence of disease in 22 patients with a mean followup of 37 months (52). It is important to note that recurrences in esthesioneuroblastoma can occur 10 to $20 \mathrm{yr}$ later (53) and therefore the true efficacy of endoscopic resection cannot be compared to formal open craniofacial resection until sufficient followup has been achieved. Advantages of endoscopic resection include improved cosmesis, reduced brain manipulation, lower morbidity, shorter surgical time, quicker recovery and shorter hospital stay, ability to precisely localize tumor origin which can be surprisingly focused despite bulky disease $(43,46,49)$. Involvement of facial skin, need for orbital exenteration, extensive lateral extension have been mentioned as contraindications to an endoscopic resection of these lesions (44).

\section{PARASELLAR LESIONS}

Parasellar lesions include meningiomas, craniopharyngiomas, epidermoid cysts, and pituitary macroadenomas. Endoscopically, these are accessed by transgressing the planum sphenoidale, tuberculum sphenoidale and/or the sella turcica (Fig. 4). For pituitary macroadenomas without extensive suprasellar extension, transnasal endoscopic resection clearly is both safe and efficacious making it the preferred method of extirpation $(9,54)$. In our experience with parasellar lesions, we have discovered that hydroscopy is

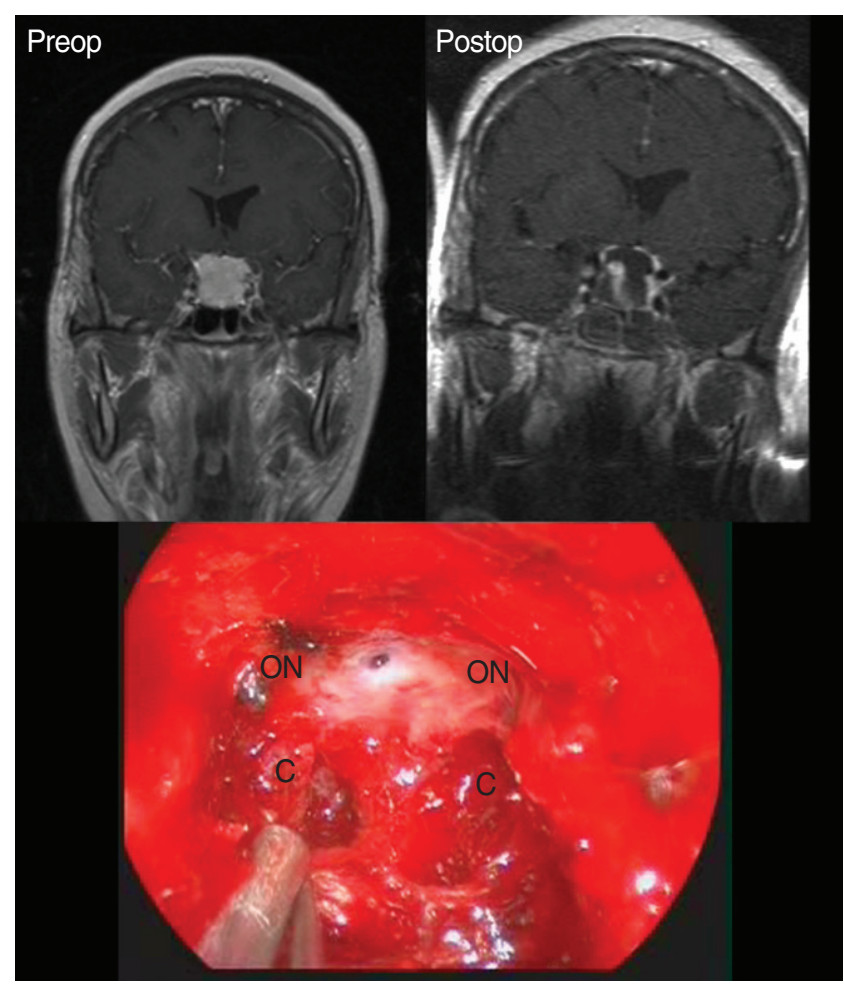

Fig. 4. Removal of tuberculum meningioma. Preop and post op MRI of a tuberculum meningioma which was recurrent after a resection several years ago via a subfrontal craniotomy approach. This was resected via a transplanum approach. In the endoscopic view, the carotids (C) and optic nerves (ON) are marked as seen during tumor dissection.

useful in determining intraoperatively, the completeness of resection. Hydroscopy is performed by irrigating the field with normal saline under gentle pressure which lifts tissues out of the way, washes away minimal bleeding and distends the cavity to allow for complete inspection (Fig. 5). Craniopharyngiomas are benign epithelial tumors that account for $2-5 \%$ of all intracranial neoplasms and routinely have a significant suprasellar component. Though they are benign tumors, they tend to have serious consequences due to their location near vital intracranial structures and optimal treatment protocols remain controversial. It is clear that gross total removal of the tumor is superior to partial removal or evacuation with $10 \mathrm{yr}$ disease free of $100 \%$ for patients with gross total removal and $38 \%$ and $77 \%$ respectively for patients with partial removal and partial removal with radiotherapy (55). Some have advocated gross total removal in all circumstances while others have suggested that the risks of total removal be weighed against the morbidity of more aggressive surgical intervention. Traditional approaches to suprasellar lesions include the subfrontal and the pterional approach, both of with are restricted by the optic chiasm making its relative position, pre or post fixed, of surgical importance. However, the position of the optic chiasm has been found to be of relatively less importance when the lesion is approached from below via an endoscopic approach and a classification scheme based on position of the lesion rela- 

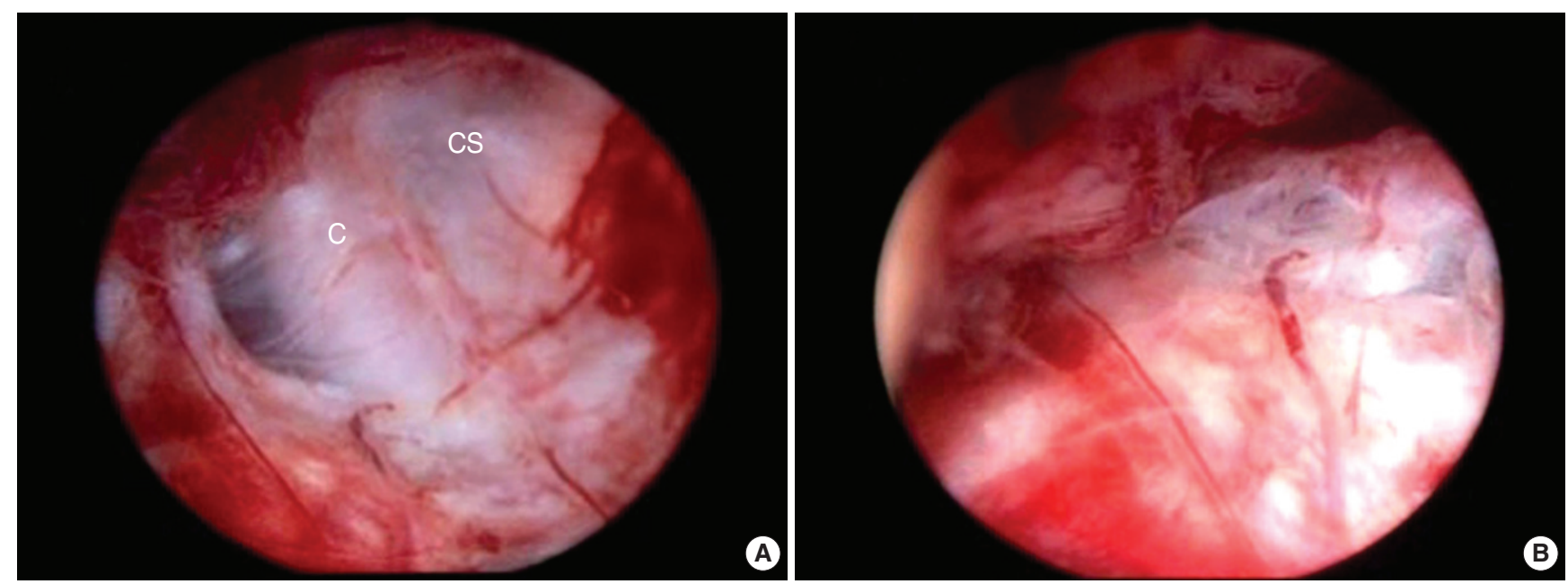

Fig. 5. Hydroscopy. In this case hydroscopy was performed after removal of a giant pituitary adenoma by irrigating the sella with normal saline and using a 45 deg endoscope to obtain 360 deg views around the entire periphery to confirm no residual pockets of tumor. (A) The cavernous carotid (C) and cavernous sinus (CS) are seen. (B) View of the floor of the sella.

tive to the infundibulum has been proposed (56). "Type I is preinfundibular; Type II is transinfundibular (extending into the stalk); Type III is retroinfundibular, extending behind the gland and stalk, and has 2 subdivisions (IIIa, extending into the third ventricle; and IIIb, extending into the interpeduncular cistern); and Type IV is isolated to the third ventricle and/or optic recess and is not accessible via an endonasal approach." The same authors have also proposed an endoscopic transposition of the pituitary to reach Type IIIlb lesions that extend into the interpeduncular cistern (57). Using this approach, they were able to achieve greater than $95 \%$ resection of four craniopharyngiomas, two of which were recurrences, with improvement of visual function in all and loss of pituitary function in one. Laufer et al. removed 10 suprasellar lesions, mostly craniopharyngiomas and meningiomas, and achieved visual function improvement in all patients with preoperative deficits with a $10 \%$ CSF leak rate and $40 \%$ panhypopituitarism rate (58). Frank et al. presented a series of 10 patients with craniopharyngiomas in 2006 where they achieved total resection in $70 \%$ with visual function improvement in all. Their complications were CSF leak in 30\%, permanent endocrine dysfunction in 30\% and one patient had meningitis (59). De Divitiis et al. had similar results in 20 patients who underwent transnasal endoscopic resection of various suprasellar lesions. All but one patient had improved or unchanged vision. Total resection was achieved in 16 . There was a $5 \%$ incidence of CSF leak and $25 \%$ incidence of postoperative endocrine dysfunction (60). The same authors published another report on suprasellar craniopharyngiomas that added 3 patients to the previous series which had 7 cases of that pathology for a total of 10 patients. In this cohort, total resection was achieved in $70 \%$ and visual function was improved or unchanged in all except one patient who had improvement in one eye and worsening in the other. Complications were a $20 \%$ CSF leak rate, $30 \%$ rate of endocrine dysfunction and one patient with brainstem hemorrhage 5 weeks post op resulting in death (61). The most recent series is on seven patients where total resection was achieved in 57\% and visual function improved in $67 \%$. Complications in that series were a CSF leak rate of $28.6 \%$ and no incidence of permanent endocrine dysfunction (62). Lesions in this area are well suited to endoscopic removal as all approaches transverse a large distance due to the central location of the parasellar region. Microscopic techniques suffer from progressive narrowing of the field of view as distance increases while the endoscope is able to provide a panoramic view due to its ability to deliver light and receive optical input at the distal end of the scope. This allows improved visualization of the lesion and neurovascular structures. Advantages of the endoscopic approach are decreased nasal morbidity when compared to microscopic transsphenoidal approaches, decreased brain manipulation when compared to transcranial approaches, and less need to work around major neurovascular structures when compared to the transcranial approaches. Poor pneumatization of the sphenoid sinus has been noted as a possible contraindication to the endoscopic approach as well as extension far into the third ventricle or adherence to neurovascular structures. The efficacy of endoscopic resection of suprasellar lesions appears to compare favorably to more traditional approaches however longer followup and larger numbers are required to truly address that question.

\section{CLIVAL LESIONS}

The major lesions of the clivus are chordomas and chondrosarcomas. Chordomas are a rare tumor of the skull base representing less than $1 \%$ of intracranial tumors. They arise from remnants of the embryonic notochord and though they rarely metastasize, they have a propensity for local recurrence and insinuation into 
bone along lines of least resistance. On average, untreated chordomas result in death approximately two years after diagnosis and even with aggressive treatment prognosis is poor with 10 yr survival between $18 \%$ and $35 \%$. Chondrosarcomas are even less common tumors of the skull base that are thought to arise either from primitive mesenchymal cells or embryonic rests of cartilage at the skull base (63). The optimal treatment for these lesions appears to be gross total surgical resection followed by proton therapy (64). The clivus is most easily approached transphenoidally however the narrowing field of view using a microscope from this anterior approach made pterional and retrosigmoid approaches necessary for tumors with significant lateral extension. Despite this weakness, the transphenoidal approach is the most commonly used approach for resection of these tumors. Several reports of endoscopic resection of these lesions have been published (20, 24, 57, 65-67). The largest series represents 11 patients with a mean followup of 27 months (65). They reported radical resection in 5 patients one of which was in a recurrent tumor that had been previously treated with surgery. Seven patients were free of disease at last followup and no patients suffered neurologic deficits post operatively. Their complications included one internal carotid artery (ICA) injury necessitating an aborted operation and subsequent endovascular repair and two CSF leaks. Another series looked at four patients with chordomas located in the interpeduncular cistern. That study reported total resection in $75 \%$ and complication included transient cranial nerve VI (CN VI) palsy and a 75\% CSF leak rate. Unfortunately, followup data on possible recurrence was not presented (57). The most recent study demonstrated no evidence of disease in seven of nine patients treated endoscopically with a followup period ranging from 3 to 39 months (20). The data on efficacy of endoscopic resection in these lesions is still evolving and obviously, longer followup and greater numbers are needed before any meaningful comparison to historical data can be performed. However, the data produced to date is promising and postoperative complication rates are favorable when compared to other approaches.

\section{SPINOMEDULLARY JUNCTION LESIONS}

The most common surgical lesion of this region is odontoid pannus usually secondary to rheumatoid arthritis. Traditionally, this is approached via a transoral route. An endoscopic endonasal approach to this area was first proposed by Alfieri et al. (68) using cadaveric studies. The first such operation was reported in 2005 (39) and since then several other groups have reported success with similar procedures (69-71). The major advantages of the endonasal route include quicker recovery, faster return to oral alimentation, lower incidence of velopharyngeal insufficiency with the major drawback being limitation at the caudal end of the dissection making the procedure not available to all patients.
Preop radiographic evaluation can determine whether or not a given patient's anatomy is amenable to this approach (72).

Another lesion, nasopharyngeal carcinoma is treated primarily with radiation however surgical salvage is the only possibly curative option left to patients who fail radiotherapy. A recent study of six patients suggests that endoscopic resection of rT1 and rT2a disease can be effective with a local control rate of $83.3 \%$ with a mean followup of 29 months (73).

\section{PETROUS APEX LESIONS}

The classic lesion of this area is the cholesterol granuloma however chordomas, chondrosarcomas and meningiomas are also among the lesions found here. The first description of endoscopic transsphenoidal management of a petrous apex cholesterol granuloma was by Griffith et al. (40). Since then several other groups have reported their experience with this technique $(21,34,74-76)$. Traditional routes to the petrous apex have included transmastoid approaches that must navigate around the facial nerve and part or all of the otic capsule or middle fossa approaches that involve brain retraction and craniotomy. The transsphenoidal approach can be faster and safer but only in selected cases. Anatomic variability in pneumatization of the temporal and sphenoid bone along with the location of the lesion and the carotid should be used to guide what is the best approach.

\section{PTERYGOPALATINE AND INFRATEMPORAL FOSSAL LESIONS}

This region represents the lateral extent of endoscopic approaches thus far and is host to lesions such as paragangliomas, schwannomas, sphenoid wing meningiomas, and juvenile nasopharyngeal angiofibromas (Fig. 6). There are several reports of such lesions being removed endoscopically (77-79). A recent review on endoscopic management of juvenile nasopharyngeal angiofibromas concluded that the vast majority of these lesions can be managed safely and effectively via an endoscopic approach (80). The major concerns with endoscopic surgery in this region are the difficulty in controlling hemorrhage from the abundant and highly variable vasculature and difficulty in physically accessing the lesion as the dissection proceeds more laterally (29).

\section{RECONSTRUCTION}

One of the major concerns in endoscopic skull base surgery is the need for robust reconstruction of the dural defect. The technology and techniques to create large defects in the cranial base have been available for quite some time. However, it is only 

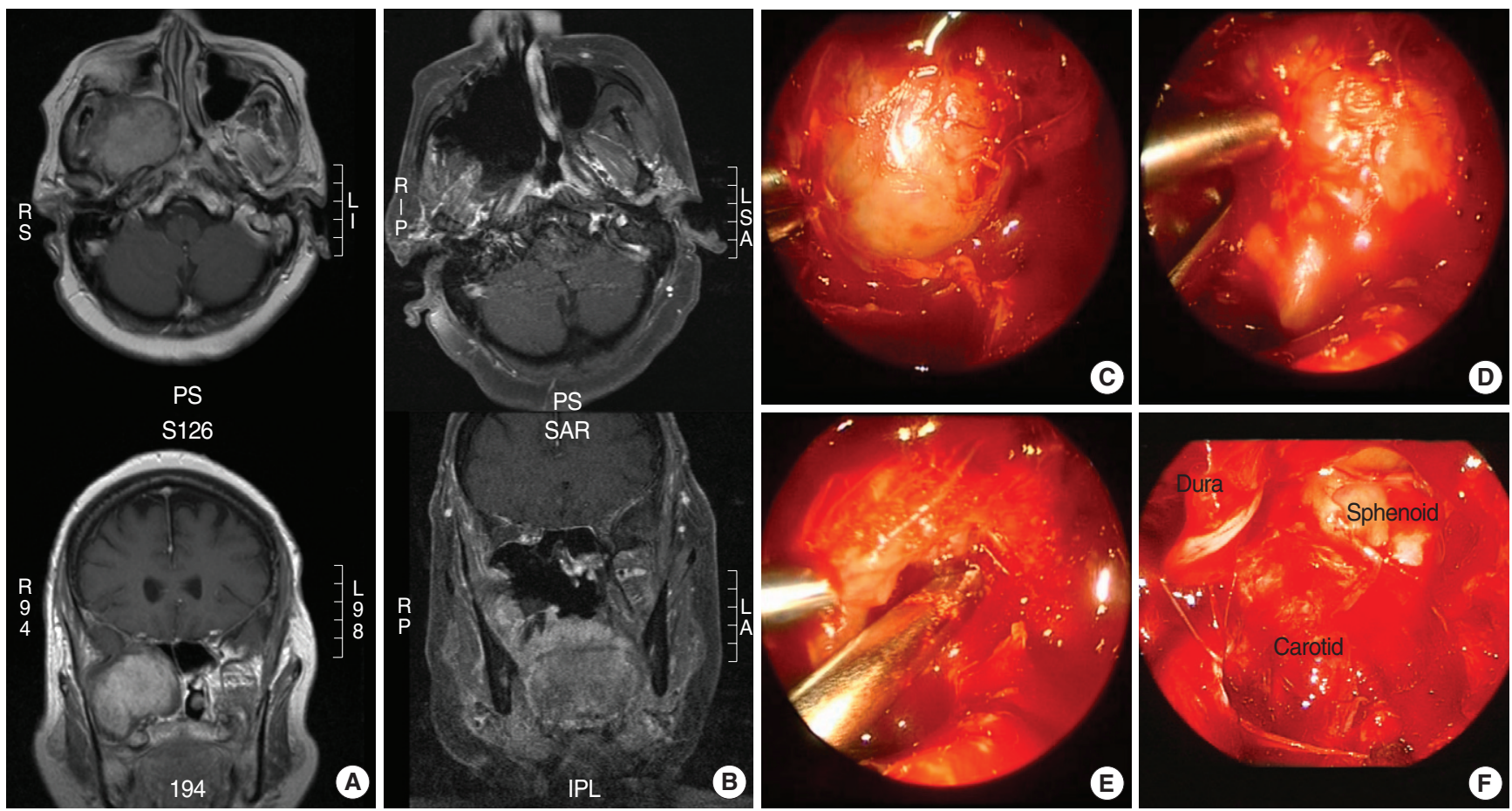

Fig. 6. Infratemporal fossa schwannoma. (A) Preop MRI of lesion. (B) Postop MRI of lesion. (C) Endoscopic view of schwannoma. (D) Lateral dissection. (E) Internal debulking. (F) Endoscopic view after resection demonstrating dehiscent dura and carotid. Patient has a well mucosalized cavity and is free of recurrence at 9 month followup. (Pictures courtesy of Dr. Mark Weissler)

recently that good options for reconstruction have been discovered. The early attempts at skull base reconstruction evolved from experience in dealing with CSF leaks and encephaloceles (Fig. 7) endoscopically (81-85). These methods utilized various materials such as dermal grafts, acellular dermis, free mucosal grafts, cartilage, fat, bone and fascia often in multiple layers to close defects at the skull base. Based on the reports, regardless of the material used, there was high success with these techniques for small defects. As defects became larger, the success of reconstruction with these techniques decreased leading to unacceptably high rates of CSF leak in large endoscopic skull base procedures (86). In open skull base surgery, vascularized flaps such as the pericranial flap, temporoparietal flap and free flaps are available as reconstructive options and it became clear that a vascularized flap was necessary to ensure reliable reconstruction of larger defects. The first such option was a septal mucosal flap based posteriorly off the posterior septal artery (87). This reconstructive option is now the workhorse of endoscopic skull base reconstruction and has dramatically improved CSF leaks rates to rates comparable to open procedures. This option is not always available. A more recent report described transposing the temporoparietal flap through the infratemporal fossa and pterygopalatine fossa and then endoscopically placing the flap for reconstruction (88). Pericranial flaps can also be harvested endoscopically and then transposed into the nasal cavity via a small osteotomy at the nasion. The first report of such a reconstruction will soon be published by University of Pittsburgh (personal communication).

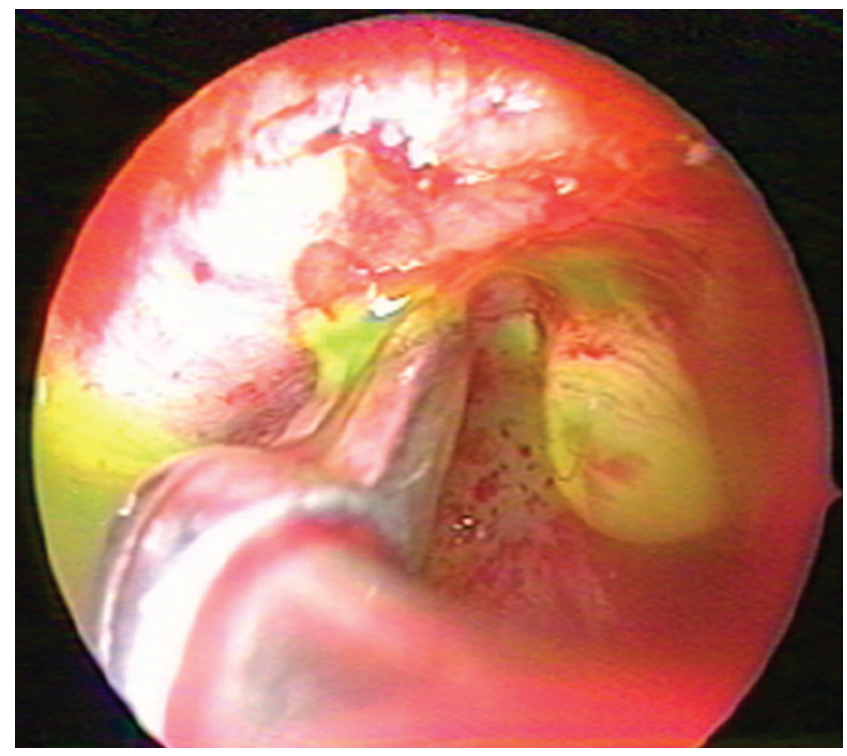

Fig. 7. Lateral sphenoid sinus encephalocele. Encephaloceles are managed by first placing a lumbar drain and instilling a dilute solution of fluorescein intrathecally. This allows for definitive indentification of the encephalocele and site of CSF drainage endoscopically. The encephalocele is followed back to the skull base dehiscence with suction and bipolar cautery and then bony defect is exposed and cleaned. A strut of cartilage and bone is then placed across the bony defect and then a mucosal graft is placed as an onlay graft and then tissue glue and merocel sponges are used to secure the graft in place. In this picture, the bipolar was placed through a transpterygoid port and the fluorescein is clearly seen as well as the carotid canal. 


\section{FUTURE DIRECTIONS}

The limits of endoscopic skull base resection are still being defined and as is often the case, the limits will likely not be realized until we have exceeded them. However, changes in what is possible and in techniques will likely come with changes in technology, much as endoscopic surgery as we know it today was largely driven by technological developments such as the Hopkins rod, powered instrumentation, and image guidance systems. There are several such developments on the horizon. Real time MRI and intraoperative ultrasound guided compensation of navigation systems would be major improvements to current navigation systems and aid in assessment of intraoperative progress during tumor resection $(89,90)$. Multidirectional rigid endoscopes tied to virtual reality systems have been reported (91). Rigid endoscopes with dual chip tips for three dimensional visualization are also in the works. Robotic surgery could also transform the way skull base surgery is performed. Currently, endoscopic surgery is ergonomically unfavorable and technically difficult with steric considerations not only in placement of the instruments intranasally but in placement of four hands in a relatively small area outside the nose. Also, current endoscopic instruments used in skull base surgery have no wrist and therefore have limited dexterity, although endoscopic instruments with such capabilities have been developed for natural orifice transluminal endoscopic surgery. Robotic surgery allows suturing which would be useful in the reconstructive phase of the operation. Indeed, cadaveric studies demonstrating the feasibility and advantages of robotic skull base surgery and one operation on an infratemporal fossa lesion have been published $(92,93)$. Current robotic systems were developed for thoracic and abdominal surgery and their size and geometry are ill suited for transnasal endoscopic skull base surgery however, this will change with continued refinement of the systems. Looking at what's ahead, it is not difficult to imagine having a system that allows high dexterity surgical manipulation with a maneuverable three dimensional endoscope being used for skull base surgery.

\section{CONCLUSION}

Transnasal endoscopic skull base surgery is a field that has experienced an explosion of development over the past several years and is still being defined in terms of its scope. The range of anatomic regions and pathology that can be addressed by endoscopic approaches is already impressive and currently questions about its efficacy are largely unanswered. For the treatment of benign disease, endoscopic treatment has largely gained acceptance; it is in malignant disease that endoscopic management remains controversial and where data is most needed to answer these concerns. However, this is a question that can only be answered with more patients and longer followup will hopefully be seen over the next several years. What we do know is that in experienced hands, resection of disease is technically feasible and safe when the disease has not spread beyond the limits of the technique: caudal to the body of $\mathrm{C} 2$, anterior and superior to the frontal outflow tract, lateral to the orbits, and anterior wall of the maxillary sinus or superficial skin. It is important to keep in mind that a minimally invasive approach should not be used as a reason for minimal surgery. The extent of resection should be equal or better than the extent of resection via an open approach and if the surgeon feels that the endoscopic approach will limit the completeness of surgery, an alternative approach should be utilized. Finally, when considering the approach to use, generally the approach that traverses the fewest neurovascular structures to access the lesion will be the best approach. For the vast majority of midline skull base lesions, this will be the endoscopic approach from below.

\section{REFERENCES}

1. Pollock JR, Akinwunmi J, Scaravilli F, Powell MP. Transcranial surgery for pituitary tumors performed by Sir Victor Horsley. Neurosurgery. 2003 Apr;52(4):914-25.

2. Caton R, Paul FT. Notes of a case of acromegaly treated by operation. Br Med J. 1893;2:1421-3.

3. Schloffer H. On the problem of surgery on the pituitary gland. Beitr Klin Chir. 1906;50:767-817.

4. Schloffer H. Further report on the patient operated upon for a pituitary tumor. Wien Klin Wochenschr. 1907;20:1075-8.

5. Hirsch O. Endonasal method of removal of hypophyseal tumors: With a report of two successful cases. JAMA. 1910;55:772-4.

6. Cushing H. Partial hypophysectomy for acromegaly: With remarks on function of the hypophysis. Ann Surg. 1909;50:1002-17.

7. Cushing H. The Weir Mitchell Lecture: Surgical experiences with pituitary disorders. JAMA. 1914;63:1515-25.

8. Maroon JC. Skull base surgery: past, present, and future trends. Neurosurg Focus. 2005 Jul 15;19(1):E1.

9. Senior BA, Ebert CS, Kolln K, Bassim MK, Younes M, Sigounas DG, et al. Minimally invasive pituitary surgery. Laryngoscope. in press.

10. Liu JK, Das K, Weiss MH, Laws ER Jr, Couldwell WT. The history and evolution of transsphenoidal surgery. J Neurosurg. 2001 Dec;95(6): 1083-96

11. Landolt AM. History of pituitary surgery from the technical aspect. Neurosurg Clin N Am. 2001 Jan;12(1):37-44.

12. Doglietto F, Prevedello DM, Jane JA Jr, Han J, Laws ER Jr. Brief history of endoscopic transsphenoidal surgery-from Philipp Bozzini to the First World Congress of Endoscopic Skull Base Surgery. Neurosurg Focus. 2005 Dec 15;19(6):E3.

13. Mouton WG, Bessell JR, Maddern GJ. Looking back to the advent of modern endoscopy: 150th birthday of Maximilian Nitze. World J Surg. 1998 Dec;22(12):1256-8.

14. Linder TE, Simmen D, Stool SE. Revolutionary inventions in the 20th century. The history of endoscopy. Arch Otolaryngol Head Neck Surg. 1997 Nov;123(11):1161-3.

15. Messerklinger W. Diagnosis and endoscopic surgery of the nose and its adjoining structures. Acta Otorhinolaryngol Belg. 1980;34(2):1706. French.

16. Jankowski R, Auque J, Simon C, Marchal JC, Hepner H, Wayoff M. Endoscopic pituitary tumor surgery. Laryngoscope. 1992 Feb;102(2): 198-202. 
17. Jho HD, Carrau RL. Endoscopic endonasal transsphenoidal surgery: experience with 50 patients. J Neurosurg. 1997 Jul;87(1):44-51.

18. Cappabianca P, Alfieri A, de Divitiis E. Endoscopic endonasal transsphenoidal approach to the sella: towards functional endoscopic pituitary surgery (FEPS). Minim Invasive Neurosurg. 1998 Jun;41(2): 66-73.

19. Laws ER Jr. Transsphenoidal microsurgery in the management of craniopharyngioma. J Neurosurg. 1980 May;52(5):661-6.

20. Zhang Q, Kong F, Yan B, Ni Z, Liu H. Endoscopic endonasal surgery for clival chordoma and chondrosarcoma. ORL J Otorhinolaryngol Relat Spec. 2008 Apr;70(2):124-9.

21. Georgalas C, Kania R, Guichard JP, Sauvaget E, Tran Ba Huy P, Herman $\mathrm{P}$. Endoscopic transsphenoidal surgery for cholesterol granulomas involving the petrous apex. Clin Otolaryngol. $2008 \mathrm{Feb} ; 33(1): 38-42$.

22. Fortes FS, Sennes LU, Carrau RL, Brito R, Ribas GC, Yasuda A, et al. Endoscopic anatomy of the pterygopalatine fossa and the transpterygoid approach: development of a surgical instruction model. Laryngoscope. 2008 Jan;118(1):44-9.

23. de Notaris M, Esposito I, Cavallo LM, Burgaya AC, Galino AP, Esposito F, et al. Endoscopic endonasal approach to the ethmoidal planum: anatomic study. Neurosurg Rev. 2008 Jul;31(3):309-17.

24. Cappabianca P, Cavallo LM, Esposito F, De Divitiis O, Messina A, De Divitiis E. Extended endoscopic endonasal approach to the midline skull base: the evolving role of transsphenoidal surgery. Adv Tech Stand Neurosurg. 2008;33:151-99.

25. Solari D, Magro F, Cappabianca P, Cavallo LM, Samii A, Esposito F, et al. Anatomical study of the pterygopalatine fossa using an endoscopic endonasal approach: spatial relations and distances between surgical landmarks. J Neurosurg. 2007 Jan;106(1):157-63.

26. Kassam AB, Thomas AJ, Zimmer LA, Snyderman CH, Carrau RL, Mintz A, et al. Expanded endonasal approach: a fully endoscopic completely transnasal resection of a skull base arteriovenous malformation. Childs Nerv Syst. 2007 May;23(5):491-8.

27. Stamm AM. Transnasal endoscopy-assisted skull base surgery. Ann Otol Rhinol Laryngol Suppl. 2006 Sep;196:45-53.

28. Stamm AC, Pignatari SS, Vellutini E. Transnasal endoscopic surgical approaches to the clivus. Otolaryngol Clin North Am. 2006 Jun;39(3): $639-56$

29. Kassam AB, Gardner P, Snyderman C, Mintz A, Carrau R. Expanded endonasal approach: fully endoscopic, completely transnasal approach to the middle third of the clivus, petrous bone, middle cranial fossa, and infratemporal fossa. Neurosurg Focus. 2005 Jul 15;19(1):E6.

30. Kassam A, Snyderman CH, Mintz A, Gardner P, Carrau RL. Expanded endonasal approach: the rostrocaudal axis. Part I. Crista galli to the sella turcica. Neurosurg Focus. 2005 Jul 15;19(1):E3.

31. Kassam A, Snyderman CH, Mintz A, Gardner P, Carrau RL. Expanded endonasal approach: the rostrocaudal axis. Part II. Posterior clinoids to the foramen magnum. Neurosurg Focus. 2005 Jul 15;19(1):E4.

32. Cavallo LM, Cappabianca P, Galzio R, Iaconetta G, de Divitiis E, Tschabitscher M. Endoscopic transnasal approach to the cavernous sinus versus transcranial route: anatomic study. Neurosurgery. 2005 Apr;56 (2 Suppl):379-89.

33. Casler JD, Doolittle AM, Mair EA. Endoscopic surgery of the anterior skull base. Laryngoscope. 2005 Jan;115(1):16-24.

34. Kingdom TT, Delgaudio JM. Endoscopic approach to lesions of the sphenoid sinus, orbital apex, and clivus. Am J Otolaryngol. 2003 SepOct;24(5):317-22

35. Alfieri A, Jho HD, Schettino R, Tschabitscher M. Endoscopic endonasal approach to the pterygopalatine fossa: anatomic study. Neurosurgery. $2003 \mathrm{Feb} ; 52(2): 374-8$.

36. Unger F, Walch C, Stammberger H, Papaefthymiou G, Haselsberger K, Pendl G. Olfactory neuroblastoma (esthesioneuroblastoma): report of six cases treated by a novel combination of endoscopic surgery and radiosurgery. Minim Invasive Neurosurg. 2001 Jun;44(2):79-84.

37. Hartnick CJ, Myseros JS, Myer CM 3rd. Endoscopic access to the in- fratemporal fossa and skull base: a cadaveric study. Arch Otolaryngol Head Neck Surg. 2001 Nov;127(11):1325-7.

38. Casiano RR, Numa WA, Falquez AM. Endoscopic resection of esthesioneuroblastoma. Am J Rhinol. 2001 Jul-Aug;15(4):271-9.

39. Kassam AB, Snyderman C, Gardner P, Carrau R, Spiro R. The expanded endonasal approach: a fully endoscopic transnasal approach and resection of the odontoid process: technical case report. Neurosurgery. $2005 \mathrm{Jul}$; 57(1 Suppl):E213.

40. Griffith AJ, Terrell JE. Transsphenoid endoscopic management of petrous apex cholesterol granuloma. Otolaryngol Head Neck Surg. 1996 Jan; 114(1):91-4.

41. Fucci MJ, Alford EL, Lowry LD, Keane WM, Sataloff RT. Endoscopic management of a giant cholesterol cyst of the petrous apex. Skull Base Surg. 1994;4(1):52-8.

42. Poetker DM, Toohill RJ, Loehrl TA, Smith TL. Endoscopic management of sinonasal tumors: a preliminary report. Am J Rhinol. 2005 May-Jun; 19(3):307-15.

43. Lund V, Howard DJ, Wei WI. Endoscopic resection of malignant tumors of the nose and sinuses. Am J Rhinol. 2007 Jan-Feb;21(1):89-94.

44. Zafereo ME, Fakhri S, Prayson R, Batra PS, Lee J, Lanza DC, et al. Esthesioneuroblastoma: 25-year experience at a single institution. Otolaryngol Head Neck Surg. 2008 Apr;138(4):452-8.

45. Castelnuovo P, Bignami M, Delu G, Battaglia P, Bignardi M, Dallan I. Endonasal endoscopic resection and radiotherapy in olfactory neuroblastoma: our experience. Head Neck. 2007 Sep;29(9):845-50.

46. Dave SP, Bared A, Casiano RR. Surgical outcomes and safety of transnasal endoscopic resection for anterior skull tumors. Otolaryngol Head Neck Surg. 2007 Jun;136(6):920-7.

47. Suriano M, De Vincentiis M, Colli A, Benfari G, Mascelli A, Gallo A. Endoscopic treatment of esthesioneuroblastoma: a minimally invasive approach combined with radiation therapy. Otolaryngol Head Neck Surg. 2007 Jan;136(1):104-7.

48. Patel SG, Singh B, Polluri A, Bridger PG, Cantu G, Cheesman AD, et al. Craniofacial surgery for malignant skull base tumors: report of an international collaborative study. Cancer. 2003 Sep 15;98(6):1179-87.

49. Batra PS, Citardi MJ, Worley S, Lee J, Lanza DC. Resection of anterior skull base tumors: comparison of combined traditional and endoscopic techniques. Am J Rhinol. 2005 Sep-Oct;19(5):521-8.

50. McCutcheon IE, Blacklock JB, Weber RS, DeMonte F, Moser RP, Byers $\mathrm{M}$, et al. Anterior transcranial (craniofacial) resection of tumors of the paranasal sinuses: surgical technique and results. Neurosurgery. 1996 Mar;38(3):471-9.

51. Har-El G, Casiano RR. Endoscopic management of anterior skull base tumors. Otolaryngol Clin North Am. 2005 Feb;38(1):133-44.

52. Snyderman CH, Carrau RL, Kassam AB, Zanation A, Prevedello D, Gardner P, et al. Endoscopic skull base surgery: principles of endonasal oncological surgery. J Surg Oncol. 2008 Jun 15;97(8):658-64.

53. Lund VJ, Howard D, Wei W, Spittle M. Olfactory neuroblastoma: past, present, and future? Laryngoscope. 2003 Mar;113(3):502-7.

54. Sonnenburg RE, White D, Ewend MG, Senior B. The learning curve in minimally invasive pituitary surgery. Am J Rhinol. 2004 Jul-Aug; 18(4):259-63.

55. Karavitaki N, Brufani C, Warner JT, Adams CB, Richards P, Ansorge $\mathrm{O}$, et al. Craniopharyngiomas in children and adults: systematic analysis of 121 cases with long-term follow-up. Clin Endocrinol (Oxf). 2005 Apr;62(4):397-409.

56. Kassam AB, Gardner PA, Snyderman CH, Carrau RL, Mintz AH, Prevedello DM. Expanded endonasal approach, a fully endoscopic transnasal approach for the resection of midline suprasellar craniopharyngiomas: a new classification based on the infundibulum. J Neurosurg. 2008 Apr; 108(4):715-28

57. Kassam AB, Prevedello DM, Thomas A, Gardner P, Mintz A, Snyderman $\mathrm{C}$, et al. Endoscopic endonasal pituitary transposition for a transdorsum sellae approach to the interpeduncular cistern. Neurosurgery. 2008 Mar; 
62(3 Suppl 1):57-72.

58. Laufer I, Anand VK, Schwartz TH. Endoscopic, endonasal extended transsphenoidal, transplanum transtuberculum approach for resection of suprasellar lesions. J Neurosurg. 2007 Mar;106(3):400-6.

59. Frank G, Pasquini E, Doglietto F, Mazzatenta D, Sciarretta V, Farneti $\mathrm{G}$, et al. The endoscopic extended transsphenoidal approach for craniopharyngiomas. Neurosurgery. 2006 Jul;59(1 Suppl 1):ONS75-83.

60. de Divitiis E, Cavallo LM, Cappabianca P, Esposito F. Extended endoscopic endonasal transsphenoidal approach for the removal of suprasellar tumors: Part 2. Neurosurgery. 2007 Jan;60(1):46-58.

61. de Divitiis E, Cappabianca P, Cavallo LM, Esposito F, de Divitiis O, Messina A. Extended endoscopic transsphenoidal approach for extrasellar craniopharyngiomas. Neurosurgery. 2007 Nov;61(5 Suppl 2):219-27.

62. Stamm AC, Vellutini E, Harvey RJ, Nogeira JF Jr, Herman DR. Endoscopic transnasal craniotomy and the resection of craniopharyngioma. Laryngoscope. Epub 2008 Apr 24.

63. Colli B, Al-Mefty O. Chordomas of the craniocervical junction: follow-up review and prognostic factors. J Neurosurg. $2001 \mathrm{Dec} ; 95(6)$ : 933-43.

64. Hug EB, Loredo LN, Slater JD, DeVries A, Grove RI, Schaefer RA, et al. Proton radiation therapy for chordomas and chondrosarcomas of the skull base. J Neurosurg. 1999 Sep;91(3):432-9.

65. Frank G, Sciarretta V, Calbucci F, Farneti G, Mazzatenta D, Pasquini E. The endoscopic transnasal transsphenoidal approach for the treatment of cranial base chordomas and chondrosarcomas. Neurosurgery. 2006 Jul;59(1 Suppl 1):ONS50-7.

66. Solares CA, Fakhri S, Batra PS, Lee J, Lanza DC. Transnasal endoscopic resection of lesions of the clivus: a preliminary report. Laryngoscope. 2005 Nov; 115(11):1917-22.

67. Jho HD, Carrau RL, McLaughlin MR, Somaza SC. Endoscopic transsphenoidal resection of a large chordoma in the posterior fossa. Acta Neurochir (Wien). 1997;139(4):343-7.

68. Alfieri A, Jho HD, Tschabitscher M. Endoscopic endonasal approach to the ventral cranio-cervical junction: anatomical study. Acta Neurochir (Wien). 2002 Mar;144(3):219-25.

69. Nayak JV, Gardner PA, Vescan AD, Carrau RL, Kassam AB, Snyderman $\mathrm{CH}$. Experience with the expanded endonasal approach for resection of the odontoid process in rheumatoid disease. Am J Rhinol. 2007 Sep-Oct;21(5):601-6.

70. Fraser JF, Anand VK, Schwartz TH. Endoscopic biopsy sampling of tophaceous gout of the odontoid process. Case report and review of the literature. J Neurosurg Spine. 2007 Jul;7(1):61-4.

71. Messina A, Bruno MC, Decq P, Coste A, Cavallo LM, de Divittis E, et al. Pure endoscopic endonasal odontoidectomy: anatomical study. Neurosurg Rev. 2007 Jul;30(3):189-94.

72. Gardner PA, Kassam AB, Rothfus WE, Snyderman CH, Carrau RL. Preoperative and intraoperative imaging for endoscopic endonasal approaches to the skull base. Otolaryngol Clin North Am. 2008 Feb;41 (1):215-30.

73. Chen MK, Lai JC, Chang CC, Liu MT. Minimally invasive endoscopic nasopharyngectomy in the treatment of recurrent T1-2a nasopharyngeal carcinoma. Laryngoscope. 2007 May;117(5):894-6.

74. Oyama K, Ikezono T, Tahara S, Shindo S, Kitamura T, Teramoto A. Petrous apex cholesterol granuloma treated via the endoscopic transsphenoidal approach. Acta Neurochir (Wien). 2007 Mar;149(3):299-302.

75. Presutti L, Villari D, Marchioni D. Petrous apex cholesterol granuloma: transsphenoid endoscopic approach. J Laryngol Otol. 2006 Jun;120(6): e20.
76. DiNardo LJ, Pippin GW, Sismanis A. Image-guided endoscopic transsphenoidal drainage of select petrous apex cholesterol granulomas. Otol Neurotol. 2003 Nov;24(6):939-41.

77. Mouadeb DA, Chandra RK, Kennedy DW, Feldman M. Sinonasal paraganglioma: endoscopic resection with a 4-year follow-up. Head Neck. 2003 Dec;25(12):1077-81.

78. Zimmer LA, Hirsch BE, Kassam A, Horowitz M, Snyderman CH. Resection of a recurrent paraganglioma via an endoscopic transnasal approach to the jugular fossa. Otol Neurotol. 2006 Apr;27(3):398-402.

79. Robinson S, Patel N, Wormald PJ. Endoscopic management of benign tumors extending into the infratemporal fossa: a two-surgeon transnasal approach. Laryngoscope. 2005 Oct;115(10):1818-22.

80. Douglas R, Wormald PJ. Endoscopic surgery for juvenile nasopharyngeal angiofibroma: where are the limits? Curr Opin Otolaryngol Head Neck Surg. 2006 Feb;14(1):1-5.

81. White DR, Dubin MG, Senior BA. Endoscopic repair of cerebrospinal fluid leaks after neurosurgical procedures. Am J Otolaryngol. 2003 JulAug;24(4):213-6.

82. Martin TJ, Loehrl TA. Endoscopic CSF leak repair. Curr Opin Otolaryngol Head Neck Surg. 2007 Feb;15(1):35-9.

83. Lopatin AS, Kapitanov DN, Potapov AA. Endonasal endoscopic repair of spontaneous cerebrospinal fluid leaks. Arch Otolaryngol Head Neck Surg. 2003 Aug;129(8):859-63.

84. Schlosser RJ, Bolger WE. Nasal cerebrospinal fluid leaks. J Otolaryngol. 2002 Aug;31 (Suppl 1):S28-37.

85. Zweig JL, Carrau RL, Celin SE, Snyderman CH, Kassam A, Hegazy $\mathrm{H}$. Endoscopic repair of acquired encephaloceles, meningoceles, and meningo-encephaloceles: predictors of success. Skull Base. 2002 Aug; 12(3):133-9.

86. Kassam A, Carrau RL, Snyderman CH, Gardner P, Mintz A. Evolution of reconstructive techniques following endoscopic expanded endonasal approaches. Neurosurg Focus. 2005 Jul 15;19(1):E8.

87. Hadad G, Bassagasteguy L, Carrau RL, Mataza JC, Kassam A, Snyderman $\mathrm{CH}$, et al. A novel reconstructive technique after endoscopic expanded endonasal approaches: vascular pedicle nasoseptal flap. Laryngoscope. 2006 Oct;116(10):1882-6.

88. Fortes FS, Carrau RL, Snyderman CH, Kassam A, Prevedello D, Vescan A, et al. Transpterygoid transposition of a temporoparietal fascia flap: a new method for skull base reconstruction after endoscopic expanded endonasal approaches. Laryngoscope. 2007 Jun;117(6):970-6.

89. Rasmussen IA Jr, Lindseth F, Rygh OM, Berntsen EM, Selbekk T, $\mathrm{Xu} \mathrm{J}$, et al. Functional neuronavigation combined with intra-operative 3D ultrasound: initial experiences during surgical resections close to eloquent brain areas and future directions in automatic brain shift compensation of preoperative data. Acta Neurochir (Wien). 2007 Apr; 149(4): 365-78.

90. Hong J, Hata N, Konishi K, Hashizume M. Real-time magnetic resonance imaging driven by electromagnetic locator for interventional procedure and endoscopic therapy. Surg Endosc. 2008 Feb;22(2):552-6.

91. Levy ML, Nguyen A, Aryan H, Jandial R, Meltzer HS, Apuzzo ML. Robotic virtual endoscopy: development of a multidirectional rigid endoscope. Neurosurgery. 2006 Jul;59(1 Suppl 1):ONS134-41.

92. O’Malley BW Jr, Weinstein GS. Robotic skull base surgery: preclinical investigations to human clinical application. Arch Otolaryngol Head Neck Surg. 2007 Dec;133(12):1215-9.

93. Hanna EY, Holsinger C, DeMonte F, Kupferman M. Robotic endoscopic surgery of the skull base: a novel surgical approach. Arch Otolaryngol Head Neck Surg. 2007 Dec;133(12):1209-14. 